Balanced Time Perspective as a Facilitator of Immigrants' Psychological Adaptation: A Study among Ukrainian Immigrants in Poland

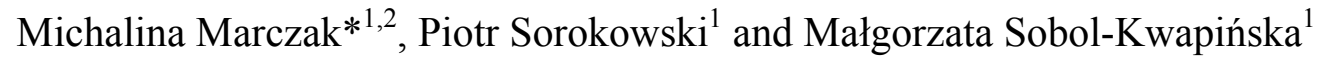

${ }^{1}$ Institute of Psychology, University of Wroclaw, ul. Dawida 1, 50-527 Wroclaw, Poland ${ }^{2}$ Institute of Psychology, Norwegian University of Science and Technology, Trondheim, Norway 


\begin{abstract}
The perception of time plays a fundamental role in the organisation of basic psychological processes, and as such may also influence migrants' psychological well-being. This paper investigates the relationship between the perception of time and immigrants' psychological adaptation (i.e. affective aspects of migration) based on a sample of 238 Ukrainians residing in Poland. To assess time perception we drew primarily from time perspective theory which defines time perspective as a measure of the degree to which individuals non-consciously construe the past, the present and the future. Psychological adaptation was assessed with focus on participants' basic psychological needs satisfaction, satisfaction with life and psychological condition. We observed relatively strong negative relationship between negative past and fatalistic present time perspectives and psychological adaptation. Additionally, it was found that more balanced and less negative temporal profile, was related to significantly better psychological adaptation of immigrants. We discuss the results in light of cultural validity of time perspective theory, destructive impact of negative time perspective on migrants' psychological wellbeing and potential application of time perspective-based therapy in integration interventions for immigrants.
\end{abstract}

Keywords: psychological adaptation, time perspective, immigrants, temporal profiles, Balanced Time Perspective, well-being, ZTPI, DBTP, DNTP, immigrant well-being 
According to the United Nations, the number of international migrants worldwide exceeded 244 million and is likely to rise in the future (UN DESA, 2015). Poland is no exception from this trend. Despite radical anti-immigration rhetoric largely present in the Polish political discourse (Krzyżanowski, 2017), in recent years the country has become home for thousands of foreigners. The exact numbers are difficult to estimate, due to circular and mobile nature of these migrations, as well as potentially large number of undocumented migrations (Pędziwiatr, 2014). The biggest number of immigrants in Poland come from the former Soviet Union, especially from Ukraine, where recent Russian annexation of Crimea and the subsequent outbreak of armed conflict in the Donbass area led to a severe breakdown of the Ukrainian economy (Polish Office for Foreigners, 2017). In 2016 Polish authorities issued 1.26 million temporary work permits to Ukrainians, whereas in the first five months of 2017 their number increased by half and is expected to surge yet more in the coming years (Polish Office for Foreigners, 2017). Whereas immigration to Poland and integration policies regarding it are in the early stages of development (Polish Ministry Of Internal Affairs, 2012), experience of other immigrant-receiving countries shows that disregarding integration problems may result in much more serious problems in the future (e.g. Koopmans, 2010).

\section{Immigrant Adaptation}

Central to the concept of migrant integration is the notion of adaptation to living in the receiving country. Although the majority of immigrants learn the culturally appropriate skills needed to operate effectively in the receiving country, many struggle with stress and coping to the extent that it affects their mental health (Bhugra, 2004; Lindert, von Ehrenstein, Priebe, Mielck, \& Brähler, 2009; Sam, Vedder, Liebkind, Neto, \& Virta, 2008). This is why immigrant adaptation was divided into two categories: socio-cultural and psychological adaptation. Socio-cultural adaptation refers to behavioural aspects of moving to a new country 
and is often described in the context of social learning and social cognition (Searle \& Ward, 1990). In contrast, psychological adaptation can be defined as "the process through which individuals seek to satisfy their needs, pursue their goals and manage demands encountered after relocating to a new society" (Ryan, Dooley, \& Benson, 2008, pp. 7). Psychological adaptation is thus related to affective aspects of migration as well as migrants' psychological wellbeing, whereas socio-cultural adaptation is concerned with cultural flexibility and behavioural competence (Ward \& Kennedy, 1993).

Various individual differences variables were found to predict migrants' psychological adaptation, for example, factors such as self-efficacy (Yusoff, 2012), self-esteem (Nguyen, Rawana, \& Flora, 2011), neuroticism and conscientiousness (Zhang, Mandl, \& Wang, 2010), optimism (Nesterko et al., 2017) and religiousness (Mölsä, Kuittinen, Tiilikainen, Honkasalo, \& Punamäki, 2017). Interestingly, many studies shown positive link between psychological adaptation and duration of migration (e.g. Aroian, Norris, \& Chiang, 2003; Chou, 2007; Gonidakis et al., 2011). What is more, several qualitative studies indicated that the ability to focus on the future positively influenced immigrants' well-being and coping (Khawaja, White, Schweitzer, \& Greenslade, 2008; Shakespeare, Finch, \& Wickham, 2010). Therefore it can be assumed that not only the physical passage of time but also the psychological perception of time (i.e. time perspective) may influence migrants' psychological adaptation in the receiving countries. If the links between the perception of time and psychological adaptation could be established, a therapy based on time perspective (e.g. Zimbardo, Sword, \& Sword, 2012) could potentially offer a promising preventive and/or therapeutic tool to improve migrants' psychological adaptation. 


\section{Time Perspective Theory}

Time perspective refers to the way people non-consciously construe the past, the present and the future (Zimbardo \& Boyd, 1999). Time perspective plays a fundamental role in the organisation of basic psychological processes (e.g. Carstensen, Isaacowitz, \& Charles, 1999). Individuals tend to develop a cognitive bias, which emphasises some temporal frames over others. These dominating time perspectives influence people's daily decisions and actions. Zimbardo and Boyd developed a questionnaire, the Zimbardo Time Perspective Inventory (ZTPI), to assess individual's perception of time (Sobol-Kwapinska et al., 2018; Zimbardo \& Boyd, 1999). Five time perspective scales were proposed: Past-Positive representing positive attitude towards the past; Past-Negative representing negative view of the past; PresentHedonistic emphasising a desire for immediate gratification and pleasure seeking; PresentFatalistic which reflects a fatalistic attitude toward the future, the belief that one has little influence on their life; Future relating to high degree of self-control, goal-orientation and consideration of future consequences of one's behaviour.

Research results indicate that time perspective is linked with many important aspects of human life. For example, past positive perspective was positively correlated with energy, having social support (Gao, 2011; Zimbardo \& Boyd, 1999), sense of safety (Bryant, Smart, \& King, 2005), and it was negatively related to neuroticism (Zhang \& Howell, 2011; Zimbardo \& Boyd, 1999). Past negative perspective was connected with fear, neuroticism, depression (McKay, Cole, \& Andretta, 2016; van Beek, Berghuis, Kerkhof, \& Beekman, 2011), gambling, propensity for addiction (Klingeman, 2001; Zimbardo \& Boyd, 1999) and low self-esteem (Stolarski, Matthews, Postek, Zimbardo, \& Bitner, 2014; Zhang \& Howell, 2011). Future perspective was positively related with optimism (Zimbardo \& Boyd, 1999, 2008), academic achievements (Barber, Munz, Bagsby, \& Grawitch, 2009), cognitive and behavioural coping strategies (Bolotova \& Hachaturova, 2013; Chua, Milfont, \& Jose, 2015) 
and health promoting behaviours (Boyd \& Zimbardo, 2005; Chen et al., 2017; Guthrie, Butler, \& Ward, 2009; Henson, Carey, Carey, \& Maisto, 2006). Present hedonistic perspective was positively correlated with risky behaviours (Rothspan \& Read 1996; Zimbardo, Keough, \& Boyd, 1997), alcohol consumption and drug abuse (Daugherty \& Brase, 2010; Keough, Zimbardo, \& Boyd, 1999). Present fatalistic perspective was positively related to neuroticism, alcohol consumption and drug abuse (Zhang \& Howell, 2011; Zimbardo \& Boyd 1999). In general, past positive perspective and future perspective are linked with positive aspects of functioning, whereas fatalistic perspective, strong hedonistic perspective and past negative perspective are connected with negative consequences.

\section{Balanced and Negative Time Perspectives}

Individual time perspective is of a mixed character that is why when studying it, it is important to examine complex time perspectives - one's attitudes towards the past as well as the present and the future. Hence the so called balanced time perspective came to be a central concept in the field of time perception research (Blomgren et al., 2016; Boniwell \& Zimbardo, 2003; Olivera-Figueroa et al., 2015; Stolarski, 2016; Zimbardo \& Boyd, 2008). Balanced time perspective combines relatively high scores on Past-Positive, Future and Present-Hedonistic and relatively low scores on Past-Negative and Present-Fatalistic scales, which allows for flexible perception of time and optimal functioning (Stolarski, 2016; Zimbardo \& Boyd, 1999). Across studies, people characterized by balanced time perspective were happier and expressed greater life satisfaction as well as positive orientation when compared to people with other temporal profiles (Boniwell, Osin, Alex Linley, \& Ivanchenko, 2010; Drake, Duncan, Sutherland, Abernethy, \& Henry, 2008; Sobol-Kwapinska \& Jankowski, 2016; Stolarski, 2016; Zhang, Howell, \& Stolarski, 2013). Similarly, the negative time perspective profile was distinguished, defined as the high Past-Negative perspective, relatively high Present-Fatalistic, 
and weak Past-Positive, Present-Hedonistic and Future perspective (Olivera-Figueroa et al., 2015; Oyanadel \& Buela-Casal, 2014; Zimbardo et al., 2012). This profile was correlated positively with depression and bipolar disorder (Oyanadel \& Buela-Casal, 2014). For this reason, helping people to move from the negative time perspective and develop more balanced time perspective became a major goal of the time perspective therapy (Zimbardo et al., 2012).

\section{The Present Study}

The present study aims to investigate the relationship between time perspective and psychological adaptation of immigrants based on a sample of Ukrainians residing in Poland. Psychological adaptation was measured with focus on participants' basic psychological needs satisfaction, satisfaction with life and psychological condition. Such indicators were proposed in previous studies on psychological adaptation of immigrants (e.g. Ryan et al., 2008; Sam et al., 2008).

Several recent studies looked into the relationship between time perspective and the adaptation of immigrants. Research among Syrian refugees revealed that past negative and fatalistic perspectives were predictors of posttraumatic stress disorder symptoms (Papastamatelou, Unger \& Zachariadis, 2018). Figueroa (2018) found that balanced time perspective predicted adaptive coping among Puerto Ricans living in the United States. And a study among Eastern European migrants in several Italian cities stressed an importance of a sense of temporariness in understanding migrant's experiences and their behaviours (Cojocaru, 2018).

The immigration context means that the relationship between time perspective and adaptation is perhaps even stronger than in the context of living in one's own country. This is because immigration is linked with confrontation with major changes in various spheres of life. The experience of change intensifies the perception of reality through the prism of time. That 
is, the change in the present increases the contrast between the past - much different than the present in a foreign country - and the uncertain future in a new environment. That is why attitudes toward the past, present and future play an important role in adaptation to this new environment.

We decided to analyse ZTPI scores in three ways. First, we employed the correlational approach. Second, since individuals exhibit a certain pattern of scores on all five ZTPI scales simultaneously, we used the so-called person-oriented analysis (e.g. Boniwell et al., 2010; McKay, Andretta, Magee, \& Worrell, 2014) to identify participants with similar temporal profiles and subsequently examine differences in their psychological adaptation. In order to identify the structure of time perspective typology, we conducted latent class analysis (LCA). Third, we applied the algorithm designed by Stolarski, Bitner and Zimbardo (2011) - a Deviation from the Balanced Time Perspective index (DBTP) and the algorithm designed by Oyanadel and Buela-Casal (2014) - a Deviation from the Negative Time Perspective index (DNTP). The DBTP is a deviation coefficient of a given individual time perspective profile from a balanced time perspective according to Zimbardo and Boyd (2008), and DNTP is a deviation coefficient from a negative time perspective according to Zimbardo et al., (2012). Based on previous research in these approaches, we hypothesised that (H1) negative time perspective would be associated with poorer psychological adaptation and (H2) more balanced temporal profile would facilitate psychological adaptation.

The situation of immigrants from Ukraine may be difficult in Poland due to the history of Polish-Ukrainian conflicts. Many people are still reluctant to thinking positively about the other nation and a sense of regret and suffering from the other nation are not uncommon. Therefore, attitudes toward the past, present and future are an important part of coping with the new reality by Ukrainian immigrants. At the same time, balanced time perspective provides flexibility, which is very important when adapting to a new environment. 
This kind of time perspective consists of a strong concentration on the positive past and positive future. The former allows a sense of security and identity, the latter enables peaceful action 'here and now' without fear of what may happen, which are particularly important in a new place of life.

\section{Methods}

\section{Participants}

The participants were 238 Ukrainians ( 81 men) residing in Poland (aged between 17 and 58, $M=27.39, S D=8.41)$. Mean time of their stay in Poland was 4 years $(\min =1, \max =26)$. Most of them (44\%) stated that the main reason of their migration was to study in Poland, 29\% migrated for economic reasons, $7 \%$ were escaping war and persecutions, whereas $20 \%$ had a different (unspecified) reason for migration. The participants were recruited through opportunistic and snowball sampling with the help of Ukrainian students at a university in the West of Poland and migrant assisting organisations in Poland.

\section{Measures}

To assess participants' psychological adaptation, we asked them to fill in the following questionnaires in one of the official languages of Ukraine (Ukrainian or Russian, depending on their personal choice):

Basic Psychological Need Satisfaction Scale. It is a 21-item scale with items such as: "I get along with people I come into contact with", "I have been able to learn interesting new skills recently", and "There is not much opportunity for me to decide for myself how to do things in my daily life" (Deci \& Ryan, 2000; Gagné, 2003). The scale was designed to assess whether an individual has the opportunity to satisfy their needs and pursue their goals. 
Respondents answer on a 7-point Likert scale (from 1 = "very untrue" to 7 = "very true").

Satisfaction with Life Scale. It is a 5-item tool to measure global life satisfaction (Balatsky \& Diener, 1993; Diener, Emmons, Larsen, \& Griffin, 1985). The items are rated on a 7-point Likert scale (from $1=$ "very untrue" to 7 = "very true"). Some examples of the items of this scale are: "I am satisfied with my life", “The conditions of my life are excellent".

Immigrant psychological condition scale. The scale consists of 15 items proposed by Virta, Sam, \& Westin (2004) to measure depression, anxiety and psychosomatic symptoms among people of immigrant background. Respondents answer on a 7-point Likert scale (from 1 = "very untrue" to 7 = "very true"). Sample items from this scale are "I feel lonely even if I am with people", "I feel tense or anxious" and "I feel tired".

Zimbardo Time Perspective Inventory. To assess participants' time perspective, we used the Zimbardo Time Perspective Inventory (Zimbardo \& Boyd, 1999). The inventory comprises 56 items rated on a 5-point Likert scale (from $1=$ "very untrue" to 5 = "very true"). The ZTPI scales are as follows: Past-Positive (9 items, e.g., "I like family rituals and traditions that are regularly repeated.") for measuring a concentration on the positively evaluated past; Past-Negative (10 items, e.g., "Things rarely work out as I expected.”) for testing focusing on the negatively evaluated past; Present-Hedonistic (15 items, e.g., "I often follow my heart more than my head.") for measuring concentration on current pleasures; Present-Fatalistic (9 items, e.g., "Often luck pays off better than hard work.") for testing passivity in the present related with the belief that everything depends on fate; Future (13 items, e.g., "It upsets me to be late for appointments.") for measuring planning and thinking about future. For the purpose of the study the Ukrainian and Russian-for-Ukrainians versions of the questionnaire were used (Senyk et al., 2017; Sircova \& Mitina, 2008).

Demographics. Moreover, we asked the participants to report on demographic variables such as their gender, age, level of education and year of arrival to Poland. We also 
controlled changes in socio-economic status (SES) between before and after migration using the MacArthur Scale of Subjective Social Status, which is a popular and reliable tool to measure the subjective social status using a numbered stepladder image (Adler, Epel, Castellazzo, \& Ickovics, 2000; Franzini \& Fernandez-Esquer, 2006; Giatti, do Valle Camelo, de Castro Rodrigues \& Barreto, 2012). The participants marked their SES before and after migration; the change in SES was assessed through subtracting the value of SES before migration from the value of SES after migration. The higher the value of change in SES, the greater the improvement in social status upon arrival in Poland.

\section{Procedure}

The study received the approval of the institutional ethics committee of the relevant university, and all participants provided informed consent. Data were collected anonymously through an online questionnaire a link to which was sent directly to the desired recipients via e-mail. Potential respondents were motivated to participate in the study through the opportunity to learn their temporal profile after they submitted the results - we wrote a programme that presented their time perspectives on a graph along with the relevant short descriptions based on Zimbardo and Boyd's work (1999).

\section{Results}

\section{Descriptive Statistics}

IBM SPSS 25 and R language for statistical computing (R Core Team, 2013) were used for data analysis. Men scored significantly higher than women only on the immigrant psychological condition scale $(t=-2.25, p<.05)$ and Past-Positive $(t=2.10, p<.05)$ scales. 
Descriptive statistics for all variables are shown in Table 1. In most cases values of kurtosis were near the expected value of 3 and the value of skewness did not exceed the conventional absolute value .8 , which indicates that the distributions of variables were close to normal. We conducted correlational analyses using Pearson or Spearman bivariate correlations as indicated for normally or non-normally distributed data respectively.

\section{Correlations Between Variables}

Correlations between demographic variables, ZTPI scales and dependent variable scores are shown in Table 1. Due to high collinearity between dependent variables, we used principal component analysis to form a composite labeled psychological adaptation (eigenvalue 1.98; 66\% explained variance; factor loadings: .61 for psychological needs satisfaction, .56 for satisfaction with life, .56 for psychological condition). Higher scores indicate greater psychological adaptation.

Intercorrelations among ZTPI scores were weak, except for the correlation between Past-Negative and Present-Fatalistic scales where we observed a moderate positive correlation. Absolute values of correlations among ZTPI and dependent variable scores ranged from negligible to considerable $(.01<r<.54)$. Absolute values of correlation coefficients among demographic variables and dependent variable scores were weak $(.03<r<.16)$, and so were the absolute values of correlation coefficients among demographic variables and ZTPI scores $(.02<r<.3)$ as well as intercorrelations among demographic variables $(.06<r<.23)$.

\section{Time Perspective as Predictor of Psychological Adaptation}

A multiple hierarchical regression analysis was conducted to determine the predictors of psychological adaptation (Table 2). The predictor variables were entered in two 
steps: (1) demographic variables; (2) time perspective (ZTPI scales). Only variables that were significantly correlated with psychological adaptation were included as independent variables in this model. In the first step, Education was added to the regression equation and, in the second step, Past-Negative, Future and Present-Fatalistic were included since these variables were significantly correlated with psychological adaptation.

After adding Past-Negative to the equation with Education as independent variable (step 2), we found that this time perspective was a significant predictor and explained an additional $30.6 \%$ of the variability in psychological adaptation. Present-Fatalistic perspective explained an additional $1.3 \%$ of the variance. In the final step, Education did not reach statistical significance as predictor of psychological adaptation.

\section{Person-oriented Analysis}

In order to identify the groups of individuals exhibiting similar time perspective score patterns within our sample, we employed latent class analysis (LCA). LCA allows for the classification of participants into subgroups based on a probabilistic model. Such model explains the likelihood of individual's membership to specific latent classes (Muthén \& Muthén, 2000). LCA estimates the underlying latent structure best describing the distribution of data. For this reason, LCA is considered superior to cluster analytic techniques, which group individuals based on distances or similarities between cases (see Hagenaars \& McCutcheon, 2009).

To compute LCA, we used the Mplus version 8.1 (Muthén \& Muthén, 1998-2015). Multiple fit statistics were used to assess the best fitting model (Collins \& Lanza, 2010). The smaller values on the Bayesian Information Criterion (BIC) and Akaike Information Criterion (AIC) the better fit of the model. The likelihood ratio test (LRT) was used to compare the fit 
of the models. We also analysed the entropy values. Entropy values closer to 1 indicate greater accuracy in the latent classes organisation. We examined each latent class solution for the class probabilities and the likelihood of participants within each class. The fit indices of two- to fivelatent class solution of time perspective typologies are presented in Table 3 . The three classes solution was considered optimal.

The first class was labelled balanced time perspective. Fifty-one percent of participants belonged in this classification. These persons were characterized by low PastNegative and low Present-Fatalistic perspectives, moderate Present-Hedonistic perspective, and relatively high Past-Positive and Future perspective. The second class was labelled future time perspective. Seven percent of participants fell into this group. These persons were characterized by moderate Past-Negative perspective, low Present-Hedonistic, low PresentFatalistic and low Past-Positive perspective and high Future perspective. The third class was labelled ambivalent time perspective. Fourty two percent of participants fell in this latent class. These persons were characterized by relatively high score on all time perspectives.

In our analyses of immigrants' psychological adaptation, we conducted one-way ANOVA with three temporal profiles as a grouping variable and psychological adaptation as the dependent variable. We observed a significant effect of temporal profile on the level of psychological adaptation $(F=21.33, p<.001)$. We observed a significant effect of temporal profile on the level of psychological adaptation. Tukey's post-hoc tests revealed significant differences in the level of psychological adaptation between balanced time perspective $(M=$ $31.12, S D=6.58)$ and ambivalent perspective $(M=28.24, S D=6.68)$ profiles $(p<.001)$.

Additionally, a regression analysis with time perspective profiles as independent variables and psychological adaptation as the dependent variable was conducted. Future time perspective profile (dummy variable 1), as well as ambivalent time perspective profile (dummy 
variable 2) were recoded as dichotomous dummy variables with balanced time perspective profile as a reference category. The results indicated that balanced time perspective was a significant predictor of psychological adaptation $(B=5.45 ; p<.001 ; S E=.12 ; t=45.61)$. Future time perspective profile did not differ significantly form balanced time perspective profile $(B=-.41 ; \quad \beta=-.08 ; p=.226 ; S E=.34 ; t=-1.21)$. Participants with ambivalent perspective profile were characterized by significantly lower psychological adaptation than participants with balanced time perspective profile $(B=-1.07 ; \beta=-.38 ; p<.001 ; S E=.34 ; t$ $=-6.05)$.

\section{Deviation from the Balanced Time Perspective and Deviation from the Negative Time Perspective}

We used the following formula for the calculation of the Deviation from the Balanced Time Perspective index (DBTP; Stolarski et al., 2011):

\footnotetext{
$\mathrm{x}_{1}=$ optimal Past-Negative-empirical score Past-Negative; $\mathrm{x}_{2}=$ optimal Past-Positive-empirical score PastPositive; $\mathrm{x}_{3}=$ optimal Present-Fatalistic-empirical score Present-Fatalistic; $\mathrm{x}_{4}=$ optimal PresentHedonistic-empirical score Present-Hedonistic; $\mathrm{x}_{5}=$ optimal Future - empirical score Future
}

Optimal values for scales were as follow: Past-Positive (4.6), Present-Hedonistic (3.9), Future (4.0), Past-Negative (1.95), Present-Fatalistic (1.5) (Stolarski et al., 2011). The higher the DBTP coefficient, the less balanced the time perspective. The DBTP correlated significantly negatively with basic psychological needs satisfaction $(r=-.48 ; p<.001)$, satisfaction with life $(r=-.36 ; p<.001)$ and psychological condition $(r=-.43 ; p<.001)$. 
The Deviation from the Negative Time Perspective index (DNTP; Oyanadel \& Buela-Casal, 2014) was calculated, according to the following formula:

$\mathrm{x}_{1}=$ negative Past-Negative-empirical score Past-Negative; $\mathrm{x}_{2}=$ negative Past-Positive-empirical score PastPositive; $\mathrm{x}_{3}=$ negative Present-Fatalistic-empirical score Present-Fatalistic; $\mathrm{x}_{4}=$ negative PresentHedonistic-empirical score Present-Hedonistic; $\mathrm{x}_{5}=$ negative Future - empirical score Future

The expected values for scales for the negative time perspective profile were: Past-Positive (2.8), Present-Hedonistic (2.65), Future (2.75), Past-Negative (4.35), Present-Fatalistic (3.3) (Oyanadel \& Buela-Casal, 2014). The higher the DNTP coefficient, the less negative time perspective. DNTP correlated significantly positively with basic psychological needs satisfaction $(r=.59 ; p<.001)$, satisfaction with life $(r=.46 ; p<.001)$ and psychological condition $(r=.5 ; p<.001)$.

A multiple hierarchical regression analysis was conducted with DBTP and DNTP as independent variables and psychological adaptation as the dependent variable (Table 5). As in the previous analyses, Education was added to the analyses in the first step.

After adding the deviation from the Negative Time Perspective to the Education variable (Step 2) we found that DNTP was a significant predictor and explained an additional $27.5 \%$ of the variability in psychological adaptation. The deviation form the Balanced Time Perspective explained an additional $1.2 \%$ of the variance. Education was a significant predictor of psychological adaptation only in the first step.

\section{Discussion}

The current study sought to examine the links between the psychological 
perception of time and psychological adaptation in a sample of Ukrainian immigrants in Poland. We hypothesised that negative time perspective would be associated with poorer psychological adaptation. Moreover we predicted that more balanced temporal profile, would facilitate psychological adaptation of immigrants.

In order to add to the increasing body of literature exploring the relationship between time perspective and psychological functioning, we decided to conduct both correlational and person-oriented analysis. The former made it possible to compare our results with a large body of extant literature. The latter enabled the identification of temporal profiles based on inter-subject similarity in scores on five time perspectives. Such approach is valuable because it is the combination of scores on different time perspectives that constitutes one's general perception of time, which influences emotion, cognition and behaviour (Carstensen et al., 1999). Previous studies successfully employed the person oriented-approach to select temporal profiles across ZTPI scores (e.g. Boniwell et al., 2010; Gao, 2011; McKay et al., 2014; McKay et al., 2016).

The results of correlational analysis confirmed the first hypothesis - relatively strong negative relationship was found between Past-Negative time perspective and the three measures of psychological adaptation - basic psychological needs satisfaction, satisfaction with life and psychological condition. Additionally, moderate negative relationship was observed between Present-Fatalistic time perspective and the aforementioned variables. Studies have shown that Past-Negative time perspective is associated with depressed psychological functioning in various populations, including adolescents (Laghi, Baiocco, D'Alessio, \& Gurrieri, 2009; Papastamatelou et al., 2018), college students (Linden, Lau-Barraco, \& Hollis, 2014) and cancer patients (Bitsko, Stern, Dillon, Russell, \& Laver, 2008), as well as among people of various cultural backgrounds (Sircova et al., 2015; Zimbardo \& Boyd, 1999, 2008), 
for example among people from the North-West Province of South Africa (Dissel \& Potgieter, 2007), Syria (Papastamatelou et al., 2018), and Russia (Boniwell et al., 2010). Although, the effects of specific perceptions of time may vary between different cultures (Lens, Paixao, Herrera, \& Grobler, 2012; McInerney, 2004), our results show that in the Ukrainian migrant population, Past-Negative (and Present-Fatalistic) time orientation is connected with poorer psychological adaptation in the receiving country.

To further understand the relationship between time perspective and psychological adaptation, it is crucial to take into account the patterns of scores on all 5 ZTPI scales. The person-oriented approach using latent class analysis rendered three temporal profiles: balanced time perspective, future time perspective and ambivalent time perspective. The analysis of differences in psychological adaptation between these profiles confirmed the second hypothesis that more balanced temporal profile facilitates psychological adaptation. It is worth stressing that balanced time perspective allows for flexibility in adjusting to the current situation (Figueroa, 2018; Stolarski et al., 2011; Zimbardo \& Boyd, 2008). For immigrants, adjusting to living in a new country seems to be an especially important ability (Bhugra, 2004; Lindert, von Ehrenstein, Priebe, Mielck, \& Brähler, 2009; Sam, Vedder, Liebkind, Neto, \& Virta, 2008). Our results provide further confirmation of negative consequences of unbalanced time perspective (Drake et al., 2008; Figueroa, 2018; Sobol-Kwapinska, 2016; Stolarski et al., 2011; Zimbardo \& Boyd, 2008).

The hypotheses were further confirmed by the results of analyses based on the Deviation from the Balanced Time Perspective index (DBTP; Stolarski et al., 2011) and the Deviation from the Negative Time Perspective index (DNTP; Oyanadel \& Buela-Casal, 2014). However, it should be noted, that the deviation from the negative time perspective profile was a stronger predictor of psychological adaptation than the deviation from the balanced time 
perspective. Thus for immigrants' psychological adaptation, avoiding a negative attitude towards time appears more important than having a balanced time perspective. Adjusting to new living conditions after migration is a specific period of life, and some time perspectives considered beneficial in many other conditions studied so far might be not adaptive in the context of migration. For example, a strong Past-Positive perspective may adversely affect the mental state of the immigrant, since it evokes longing for the time that has passed and is associated with a tendency to idealize the past and to compare the present with the romanticised past. Therefore, it seems that reducing negative time perspective is especially vital for immigrants' psychological adaptation.

The correlational analysis of three time orientations - Future, Past-Positive and Present-Hedonistic revealed that, taken separately, they were only vaguely linked to the measures of psychological adaptation. Interestingly, high scores on these scales (along with low scores on the remaining scales) constitute balanced time perspective. This observation suggests that the relationship between time perspective and psychological adaptation should be studied in light of ZTPI scales' relation with one another. Additionally, we observed a weak, although significant, correlation between the level of education and psychological adaptation. This relationship, however, becomes insignificant when time perspectives are included in the analysis. This observation shows that perception of time is a more important factor associated with psychological adaptation than demographic variables.

The results of our study have clinical implications. They suggest that developing a balanced time perspective could be effective in helping immigrants who struggle with psychological adaptation. One way to develop such balanced perception of time is through therapy or training based on time perspective, whose application is increasingly gaining momentum in the health care research (Sword, Sword, \& Brunskill, 2015). To date, several 
therapeutic interventions based on time perspective were put forward such as time perspective therapy (Zimbardo et al., 2012), future oriented group training (van Beek, Kerkhof, \& Beekman, 2009) and mindfulness based cognitive therapy (Segal, Williams, \& Teasdale, 2002). Notably, these therapies have been identified to be useful in the treatment of posttraumatic stress disorder, suicidal thinking and behaviour, and depression respectively (Zimbardo \& Boyd, 2008; Zimbardo et al., 2012). We suggest that a therapy or training based on time perspective could offer a potential therapeutic tool for immigrants experiencing problems with psychological adaptation in the receiving country, although future research should determine the effectiveness of such therapeutic approach. Correspondingly to the time perspective therapy hitherto used mostly to treat PTSD patients (Zimbardo et al., 2012), therapeutic intervention for immigrants could focus on balancing negative memories and full of resignation thoughts about the present with positive memories, more enthusiastic attitude to the present and a will to act actively in the future. The main goal of such therapy would be to achieve temporal balance and hence flexibility that allows for mindfully switching from one time orientation to another to face the demands of the new environment (Kazakina \& van Beek, 2017).

Our study has several limitations. First, due to resource constraints, two of the measures - the Basic Psychological Need Satisfaction Scale and immigrant psychological condition scale - were not validated for use with Ukrainian or Russian speaking subjects. Similarly, the Satisfaction with Life Scale was validated only for use with Russian speakers (Balatsky \& Diener, 1993). However, in order to ensure maximum reliability, these tools were translated from English by Ukrainian translators using the back translation procedure (Brislin, 1970). Additionally, as noted by Riley, Varner, Ventevogel, Taimur Hasan and WeltonMitchell (2017) the external validity of scales developed in one population often overlaps when 
these measures are used in other populations. Nevertheless, our results should be interpreted carefully. Moreover the study was cross-sectional. It is possible that psychological adaptation is an antecedent to time perspective. Future studies on the relationship between time perspective and adaptation could benefit from testing if time perspective accounts for psychological adaptation variance, above and beyond typical predictors of adaptation, such as e.g., acculturation strategies.

This research examined the links between time perspective and psychological adaptation of immigrants based on a sample of one ethnic origin - Ukrainian. In order to extrapolate our findings onto the general population of immigrants, more research is needed, especially in non-western samples (Henrich, Heine, \& Norenzayan, 2010).

\section{Conclusion}

Despite its limitations, our study reveals that time perspective is meaningfully related to psychological adaptation of immigrants. Whereas negative time perspective is related to depressed psychological adaptation, more balanced time perspective can be seen as a facilitator of psychological adaptation. For this reason, time perspective theory offers a potentially effective tool for promoting psychological adaptation of immigrants. One example of application of time perspective theory in practice might be a time perspective-based therapy or training. Through seeking to equip an individual with the flexibility to adapt their time perspective according to the situation, such therapy bolsters psychological functioning, which in turn might facilitate psychological adaptation in the receiving society. 


\section{Acknowledgements}

We would like to thank Filip Gromuł for his invaluable help with developing the online research programme and Maria Ischenko for her comments that helped us improve programme's user experience. Many thanks to Nika Hutsenko and Alina Metelitsa for their assistance with data collection. 


\section{References}

Adler, N. E., Epel, E. S., Castellazzo, G., \& Ickovics, J. R. (2000). Relationship of subjective and objective social status with psychological and physiological functioning: Preliminary data in healthy, White women. Health Psychology, 19(6), 586. doi:10.1037/02786133.19 .6 .586

Aroian, K. J., Norris, A. E., \& Chiang, L. (2003). Gender differences in psychological distress among immigrants from the former Soviet Union. Sex Roles, 48(1), 39-51. doi:10.1023/A:1022392528490

Balatsky, G., \& Diener, E. (1993). Subjective well-being among Russian students. Social Indicators Research, 28(3), 225-243. doi: 10.1007/BF01079019

Barber, L. K., Munz, D. C., Bagsby, P. G., \& Grawitch, M. J. (2009). When does time perspective

matter? Self-control as a moderator between time-perspective and academic achievement. Personality and Individual Differences, 46(2), 250-253. doi: 10.1016/j.paid.2008.10.007.

Bhugra, D. (2004). Migration and mental health. Acta Psychiatrica Scandinavica, 109(4), 243258. doi:10.1046/j.0001-690X.2003.00246.x

Bitsko, M. J., Stern, M., Dillon, R., Russell, E. C., \& Laver, J. (2008). Happiness and time perspective as potential mediators of quality of life and depression in adolescent cancer. Pediatric Blood \& Cancer, 50(3), 613-619. doi:10.1002/pbc.21337

Blomgren, A. S., Svahn, K., Åström, E., \& Rönnlund, M. (2016). Coping strategies in late adolescence: Relationships to parental attachment and time perspective. The Journal of Genetic Psychology, 177(3), 85-96. doi: 10.1080/00221325.2016.1178101

Bolotova, A. K., \& Hachaturova, M. R. (2013). The role of time perspective in coping behavior. Psychology in Russia, 6(3), 120. doi: 10.11621/pir.2013.0311 
Boniwell, I., Osin, E., Alex Linley, P., \& Ivanchenko, G. V. (2010). A question of balance: Time perspective and well-being in British and Russian samples. The Journal of Positive Psychology, 5(1), 24-40. doi: 10.1080/17439760903271181

Boniwell, I., \& Zimbardo, P. (2003). Time to find the right balance. The Psychologist, 16, 129131.

Boniwell, I., \& Zimbardo, P. G. (2015). Balancing time perspective in pursuit of optimal functioning. In S. Joseph (Ed.) Positive Psychology in Practice: Promoting Human Flourishing in Work, Health, Education, and Everyday Life (223-236). Hoboken, NJ: John Wiley \& Sons.

Boyd, J. N., \& Zimbardo, P. G. (2005). Time perspective, health and risk taking. In A. Strathman \& J. Joireman (Eds.), Understanding behavior in the context of time (pp. 85107). London: Lawrence E.

Brislin, R. W. (1970). Back-translation for cross-cultural research. Journal of Cross-Cultural Psychology, 1(3), 185-216. doi: 10.1177/135910457000100301

Bryant, F. B., Smart, C. M., \& King, S. P. (2005). Using the past to enhance the present: Boosting happiness through positive reminiscence. Journal of Happiness Studies, 6, 227 260. doi: $10.1007 / \mathrm{s} 10902-005-3889-4$.

Carelli, M., Wiberg, B., and Wiberg, M. (2011). Development and construct validation of the Swedish Zimbardo Time Perspective Inventory. European Journal of Psychological Assessment 27(4): 220-227. doi: 10.1027/1015-5759/a000076

Carstensen, L. L., Isaacowitz, D. M., \& Charles, S. T. (1999). Taking time seriously: A theory of socioemotional selectivity. American Psychologist, 54(3), 165. doi:10.1037/0003066X.54.3.165

Chen, T., Liu, L. L., Cui, J. F., Chen, X. J., Shi, H. S., Neumann, D. L., ... \& Chan, R. C. (2017). Moderating effect of age on the association between future time perspective and preventive 
coping. PsyCh journal, 6(3), 185-193. doi: 10.1002/pchj.172

Chou, K.-L. (2007). Psychological distress in migrants in Australia over 50 years old: a longitudinal investigation. Journal of Affective Disorders, 98(1), 99-108. doi:10.1016/j.jad.2006.07.002

Chua, L. W., Milfont, T. L., \& Jose, P. E. (2015). Coping skills help explain how futureoriented

adolescents accrue greater well-being over time. Journal of Youth and Adolescence, 44(11), 2028-2041. doi: 10.1007/s10964-014-0230-8

Cojocaru, O. (2018). Permanent Migrant Temporariness or "Why there's nothing as permanent as a temporary migrant"? Paper presented at the 4th International Conference on Time Perspective, August 27-31, Nantes, France.

Collins, L. M., \& Lanza, S. T. (2010). Latent class and latent transition analysis. Hoboken, NJ: Wiley.

Daugherty, J. R., \& Brase, G. L. (2010). Taking time to be healthy: Predicting health behaviors with delay discounting and time perspective. Personality and Individual Differences, 48 , 202-207. doi: 10.1016/j.adolescence.2015.08.015.

Deci, E. L., \& Ryan, R. M. (2000). The "what" and "why" of goal pursuits: Human needs and the self-determination of behavior. Psychological Inquiry, 11(4), 227-268. doi:10.1207/S15327965PLI1104_01

Diener, E., Emmons, R. A., Larsen, R. J., \& Griffin, S. (1985). The satisfaction with life scale. Journal of Personality Assessment, 49(1), 71-75. doi:10.1207/s15327752jpa4901_13

Dissel, J., \& Potgieter, J. C. (2007). Validation of a scale to measure time perspective in an African context (Unpublished master's thesis). North-West University, South Africa.

Drake, L., Duncan, E., Sutherland, F., Abernethy, C., \& Henry, C. (2008). Time perspective and correlates of wellbeing. Time \& Society, 17(1), 47-61. doi:10.1177/0961463x07086304 
Figueroa, L. O. (2018). Predictability of time perspective on adaptive and maladaptive stress coping styles of Puerto Ricans Living in Mainland Unites States and the Islands of Puerto Rico. Paper presented at the 4th International Conference on Time Perspective, August 2731, Nantes, France.

Franzini, L., \& Fernandez-Esquer, M. E. (2006). The association of subjective social status and health in low-income Mexican-origin individuals in Texas. Social Science \& Medicine, 63(3), 788-804. doi: 10.1037/0278-6133.19.6.586

Gagné, M. (2003). The role of autonomy support and autonomy orientation in prosocial behavior engagement. Motivation and Emotion, 27(3), 199-223. doi:10.1023/A:1025007614869

Gao, Y.-J. (2011). Time perspective and life satisfaction among young adults in Taiwan. Social Behavior and Personality, 39(6), 729-736. doi:10.2224/sbp.2011.39.6.729

Giatti, L., do Valle Camelo, L., de Castro Rodrigues, J. F., \& Barreto, S. M. (2012). Reliability of the MacArthur scale of subjective social status-Brazilian Longitudinal Study of Adult Health (ELSA-Brasil). BMC Public Health, 12(1), 1096. doi: 10.1186/1471-2458-12-1096

Gonidakis, F., Korakakis, P., Ploumpidis, D., Karapavlou, D.-A., Rogakou, E., \& Madianos, M. G. (2011). The relationship between acculturation factors and symptoms of depression: A cross-sectional study with immigrants living in Athens. Transcultural Psychiatry, 48(4), 437-454. doi:10.1177/1363461511408493

Guthrie, L. C., Butler, S. C., \& Ward, M. M. (2009). Time perspective and socioeconomic status: A link to socioeconomic disparities in health? Social Science \& Medicine, 68(12), 2145-2151. doi:10.1016/j.socscimed.2009.04.004

Hagenaars, J. A., \& McCutcheon, A. L. (2009). Applied latent class analysis. New York, NY: Cambridge University Press.

Henrich, J., Heine, S. J., \& Norenzayan, A. (2010). The weirdest people in the world? 
Behavioral and Brain Sciences, 33(2-3), 61-83. doi:10.1017/S0140525X0999152X

Henson, J. M., Carey, M. P., Carey, K. B., \& Maisto, S. A. (2006). Associations among health behaviors and time perspective in young adults: Model testing with boot-strapping replication. Journal of Behavioral Medicine, 29(2), 127-137. doi:10.1007/s10865-005$9027-2$

Kazakina, E., \& van Beek, W. (2017). Temporal Focus in Psychotherapy: Clinical Tales of Past, Present, and Future. In A. Kostić \& D. Chadee (Eds.) Time Perspective (pp. 239-266): London: Palgrave Macmillan. doi:10.1057/978-1-137-60191-9_11

Keough, K. A., Zimbardo, P. G., \& Boyd, J. N. (1999). Who's smoking, drinking, and using drugs? Time perspective as a predictor of substance use. Journal of Basic and Applied Social Psychology, 21, 149-164. doi: 10.1207/15324839951036498

Khawaja, N. G., White, K. M., Schweitzer, R., \& Greenslade, J. (2008). Difficulties and coping strategies of Sudanese refugees: A qualitative approach. Transcultural Psychiatry, 45(3), 489-512. doi:10.1177/1363461508094678

Klingeman, H. (2001). The time game: Temporal perspectives of patients and staff in alcohol and drug treatment. Time \& Society, 10, 303-328. doi: 10.1007/s11031-006-9018-9.

Koopmans, R. (2010). Trade-offs between equality and difference: Immigrant integration, multiculturalism and the welfare state in cross-national perspective. Journal of Ethnic and Migration Studies, 36(1), 1-26. doi:10.1080/13691830903250881

Krzyżanowski, M. (2017). Discursive Shifts in Ethno-Nationalist Politics: On Politicization and Mediatization of the "Refugee Crisis" in Poland. Journal of Immigrant \& Refugee Studies, 1-21. doi:10.1080/15562948.2017.1317897

Laghi, F., Baiocco, R., D'Alessio, M., \& Gurrieri, G. (2009). Suicidal ideation and time perspective in high school students. European Psychiatry, 24(1), 41-46. doi:10.1016/j.eurpsy.2008.08.006 
Lens, W., Paixao, M. P., Herrera, D., \& Grobler, A. (2012). Future time perspective as a motivational variable: Content and extension of future goals affect the quantity and quality of motivation. Japanese Psychological Research, 54(3), 321-333. doi:10.1111/j.1468$5884.2012 .00520 . x$

Linden, A. N., Lau-Barraco, C., \& Hollis, B. F. (2014). Associations between psychological distress and alcohol outcomes as mediated by time perspective orientation among college students. Mental Health and Substance Use, 7(2), 134-143. doi:10.1080/17523281.2013.785443

Lindert, J., von Ehrenstein, O. S., Priebe, S., Mielck, A., \& Brähler, E. (2009). Depression and anxiety in labor migrants and refugees-a systematic review and meta-analysis. Social Science \& Medicine, 69(2), 246-257. doi:10.1016/j.socscimed.2009.04.032

McInerney, D. M. (2004). A discussion of future time perspective. Educational Psychology Review, 16(2), 141-151. doi:10.1023/B:EDPR.0000026610.18125.a3

McKay, M. T., Andretta, J. R., Magee, J., \& Worrell, F. C. (2014). What do temporal profiles tell us about adolescent alcohol use? Results from a large sample in the United Kingdom. Journal of Adolescence, 37(8), 1319-1328. doi:10.1016/j.adolescence.2014.09.008

McKay, M. T., Cole, J. C., \& Andretta, J. R. (2016). Temporal profiles relate meaningfully to anxiety and depression in university undergraduates. Personality and Individual Differences, 101, 106-109. doi:/10.1016/j.paid.2016.05.058

Mölsä, M., Kuittinen, S., Tiilikainen, M., Honkasalo, M.-L., \& Punamäki, R.-L. (2017). Mental health among older refugees: the role of trauma, discrimination, and religiousness. Aging \& Mental Health, 21(8), 829-837. doi:10.1080/13607863.2016.1165183

Muthén, B., \& Muthén, L. K. (2000). Integrating person-centered and variable-centered analyses: Growth mixture modeling with latent trajectory classes. Alcoholism: Clinical and Experimental Research, 24, 882-891. doi: 10.1111/j.1530-0277.2000.tb02070.x 
Muthén, L. K., \& Muthén, B. O. (1998 -2015). Mplus user's guide, 7th ed. Los Angeles, CA: Author.

Nesterko, Y., Nesterko, Y., Friedrich, M., Friedrich, M., Seidel, N., Seidel, N., . . Glaesmer, H. (2017). Health-related quality of life in Jewish immigrants from the Former Soviet Union in Germany. International Journal of Migration, Health and Social Care, 13(2), 277-288. doi:10.1108/IJMHSC-11-2015-0045

Nguyen, H., Rawana, J. S., \& Flora, D. B. (2011). Risk and protective predictors of trajectories of depressive symptoms among adolescents from immigrant backgrounds. Journal of Youth and Adolescence, 40(11), 1544-1558. doi:10.1007/s10964-011-9636-8

Olivera-Figueroa, L. A., Asthana, S., Odisho, N., Ortiz Velez, A. L., Cuebas, K., \& Lopez Cordova, N. M. (2016). Emerging cross-cultural research: the role of time perspective on well-being, life satisfaction and mindfulness. Advances in Psychology Research, 113. Hauppage, New York: Nova Science Publishers.

Olivera-Figueroa, L. A., Juster, R. P., Morin-Major, J. K., Marin, M. F., \& Lupien, S. J. (2015). A time to be stressed? Time perspectives and cortisol dynamics among healthy adults. Biological Psychology, 111, 90-99. doi: 10.1016/j.biopsycho.2015.09.002

Papastamatelou, J., Unger, A., \& Zachariadis, A. (2018). The relationship between time perspective and PTSD: Evidence from Syrian refugees accommodated in Greek hotspots. Paper presented at the 4th International Conference on Time Perspective, August 27-31, Nantes, France.

Pędziwiatr, K. (2014). Imigranci w Polsce i wyzwania integracyjne [Immigrants and immigration challenges in Poland]. Studia BAS, 4(40), 135-153.

Polish Ministry Of Internal Affairs (2012). Polityka migracyjna Polski - stan obecny $i$ postulowane działania [Polish migration policy - present condition and postulated activities, report]. Warszawa: Departament Polityki Migracyjnej, Ministerstwo Spraw Wewnętrznych. 
Polish Office for Foreigners. (2017). Imigracja z Ukrainy [Immigration from Ukraine, report]. Biuletyn UDSC II kwartał 2017. Warszawa: Urząd do spraw Cudzoziemców.

Przepiórka, A., \& Blachnio, A. (2016). Time perspective in Internet and Facebook addiction. Computers in Human Behavior, 60, 13-18. doi:10.1016/j.chb.2016.02.045

R Core Team (2013). R: A language and environment for statistical computing. R Foundation for Statistical Computing, Vienna, Austria.

URL http://www.R-project.org/.Riley, A., Varner, A., Ventevogel, P., Taimur Hasan, M., \& Welton-Mitchell, C. (2017). Daily stressors, trauma exposure, and mental health among stateless Rohingya refugees in Bangladesh. Transcultural Psychiatry, 54(3), 304-331. doi:10.1177/1363461517705571

Rothspan, S., \& Read, S. J. (1996). Present versus future time perspective and HIV risk among heterosexual college students. Health Psychology, 15, 131-134.

Ryan, D., Dooley, B., \& Benson, C. (2008). Theoretical perspectives on post-migration adaptation and psychological well-being among refugees: Towards a resource-based model. Journal of Refugee Studies, 21(1), 1-18. doi:10.1093/jrs/fem047

Sam, D. L., Vedder, P., Liebkind, K., Neto, F., \& Virta, E. (2008). Immigration, acculturation and the paradox of adaptation in Europe. European Journal of Developmental Psychology, 5(2), 138-158. doi:10.1080/17405620701563348

Searle, W., \& Ward, C. (1990). The prediction of psychological and sociocultural adjustment during cross-cultural transitions. International Journal of Intercultural Relations, 14(4), 449-464. doi: 10.1016/0147-1767(90)90030-Z

Segal, Z. V., Williams, J. M. G., \& Teasdale, J. D. (2002). Mindfulness-based cognitive therapy for depression: A new approach to relapse prevention. New York: Guilford. doi:10.1080/713869628

Senyk, O., Abramov, V., Ruzhyts'ka, M., Babatina, S., Bedan, V., Bunas, A., Dvornyk, M., 
Yevchenko, I., Klymenko, O., Kuz'menko, YA., Lutsenko, O., Mandzyk, T., Okhrimenko, V., \& Riznyk R. (2017). Opytuval'nyk chasovoyi perspektyvy F. Zimbardo: rezul'taty validyzatsiyi rosiys'komovnoyi versiyi na rosiys'komovnykh Ukrayintsyakh ta perehlyadu klyuchiv ukrayins'koyi versiyi [Zimbardo Time Perspective Inventory: Results of the Russian-language version for the Russian-speaking Ukrainians and the revision of the Ukrainian version keys]. Humanitarnyy visnyk DVNZ Pereyaslav-Khmel'nyts'kyy derzhavnyy pedahohichnyy universytet imeni Hryhoriya Skovorody, 37-1, T. VI (74), 428449.

Shakespeare-Finch, J., \& Wickham, K. (2010). Adaptation of Sudanese refugees in an Australian context: Investigating helps and hindrances. International Migration, 48(1), 2346. doi:10.1111/j.1468-2435.2009.00561.x

Sircova, A., \& Mitina, O. (2008). Vozrastnaya dinamika vremennykh oriyentatsiy lichnosti [Age dynamics of time orientations]. Voprosy Psikhologii, 2, 41-55.

Sircova, A., van de Vijver, F. J., Osin, E., Milfont, T. L., Fieulaine, N., Kislali-Erginbilgic, A., \& Zimbardo, P. G. (2015). Time perspective profiles of cultures. In M. Stolarski, N. Fieulaine \& W. van Beek (Eds.), Time Perspective Theory; Review, Research and Application (pp. 169-187). Cham: Springer. doi:10.1007/978-3-319-07368-2

Sobol-Kwapinska, M. (2016). Calm down - it's only neuroticism. Time perspectives as moderators and mediators of the relationship between neuroticism and wellbeing. Personality and Individual Differences, 94, 64-71. doi: 10.1016/j.paid.2016.01.004

Sobol-Kwapinska, M., \& Jankowski, T. (2016). Positive time: Balanced time perspective and positive orientation. Journal of Happiness Studies, 17(4), 1511-1528. doi:10.1007/s10902015-9656-2

Sobol-Kwapinska, M., Jankowski, T., Przepiorka, A., Oinyshi, I. E., Sorokowski, P., \& Zimbardo, P. (2018). What is the structure of time? A study on time perspective in the USA, 
Poland, and Nigeria. Frontiers in Psychology, 1-10. doi: 10.3389/fpsyg.2018.02078

Stolarski, M. (2016). Not restricted by their personality: Balanced Time Perspective moderates well-established relationships between personality traits and well-being. Personality and Individual Differences, 100, 140-144. doi: 10.1016/j.paid.2015.11.037

Stolarski, M., Bitner, J., \& Zimbardo, P. (2011). Time perspective, emotional intelligence and discounting of delayed awards. Time \& Society, 20, 346-363. doi: $10.1177 / 0961463 X 11414296$

Stolarski, M., Matthews, G., Postek, S., Zimbardo, P. G., \& Bitner, J. (2014). How we feel is a

matter of time: Relationships between time perspective and mood. Journal of Happiness Studies, 15, 809-827. doi: 10.1007/s10902-013-9450-y.

Sword, R. M., Sword, R. K., \& Brunskill, S. R. (2015). Time perspective therapy: transforming Zimbardo's temporal theory into clinical practice. In M. Stolarski, N. Fieulaine \& W. van Beek, Time Perspective Theory; Review, Research and Application (pp. 481-498). Cham: Springer. doi:10.1007/978-3-319-07368-2

United Nations Department of Economic and Social Affairs (UN DESA) (2015). Trends in International Migrant Stock: The 2015 Revision.

van Beek, W., Berghuis, H., Kerkhof, A., \& Beekman, A. (2011). Time perspective, personality and psychopathology: Zimbardo's time perspective inventory in psychiatry. Time \& Society, 20(3), 364-374. doi:10.1177/0961463X10373960

van Beek, W., Kerkhof, A., \& Beekman, A. (2009). Future oriented group training for suicidal patients: a randomized clinical trial. BMC Psychiatry, 9(1), 65. doi:10.1186/1471-244X-965

Virta, E., Sam, D. L., \& Westin, C. (2004). Adolescents with Turkish background in Norway and Sweden: A comparative study of their psychological adaptation. Scandinavian Journal 
of Psychology, 45(1), 15-25. doi:10.1111/j.1467-9450.2004.00374.x

Wang, Y., Chen, X. j., Cui, J. f., \& Liu, L. 1. (2015). Testing the Zimbardo time perspective inventory in the Chinese context. PsyCh Journal, 4(3), 166-175. doi:10.1002/pchj.103

Ward, C., \& Kennedy, A. (1993). Psychological and socio-cultural adjustment during crosscultural transitions: A comparison of secondary students overseas and at home. International Journal of Psychology, 28(2), 129-147. doi: 10.1080/00207599308247181

Yusoff, Y. M. (2012). Self-efficacy, perceived social support, and psychological adjustment in international undergraduate students in a public higher education institution in Malaysia. Journal of Studies in International Education, 16(4), 353-371. doi:10.1177/1028315311408914

Zhang, J., Mandl, H., \& Wang, E. (2010). Personality, acculturation, and psychosocial adjustment of Chinese international students in Germany. Psychological Reports, 107(2), 511-525. doi:10.2466/07.09.11.17.PR0.107.5.511-525

Zhang, J. W., \& Howell, R. T. (2011). Do time perspectives predict unique variance in life satisfaction beyond personality traits? Personality and Individual Differences, 50(8), 12611266. doi:10.1016/j.paid.2011.02.021

Zhang, J. W., Howell, R. T., \& Stolarski, M. (2013). Comparing three methods to measure a balanced time perspective: The relationship between a balanced time perspective and subjective well-being. Journal of Happiness Studies, 14(1), 169-184. doi:10.1007/s10902$012-9322-\mathrm{x}$

Zimbardo, P., \& Boyd, J. (1999). Putting time in perspective: A valid, reliable individualdifferences metric. Journal of Personality and Social Psychology, 77, 1271-1288. doi:10.1007/978-3-319-07368-2_2

Zimbardo, P., \& Boyd, J. (2008). The time paradox: The new psychology of time that can change your life. NY: Free Press. 
Zimbardo, P. G., Keough, K. A., \& Boyd J. N. (1997). Present time perspective as a predictor of risky driving. Personality and Individual Differences, 23, (6), 1007-1023.

Zimbardo, P., Sword, R., \& Sword, R. (2012). The time cure: Overcoming PTSD with the new psychology of time perspective therapy: San Francisco, CA: John Wiley \& Sons.

\section{Tables}

Table 1. Intercorrelations among ZTPI scales, demographic variables and dependent variables, and descriptive statistics

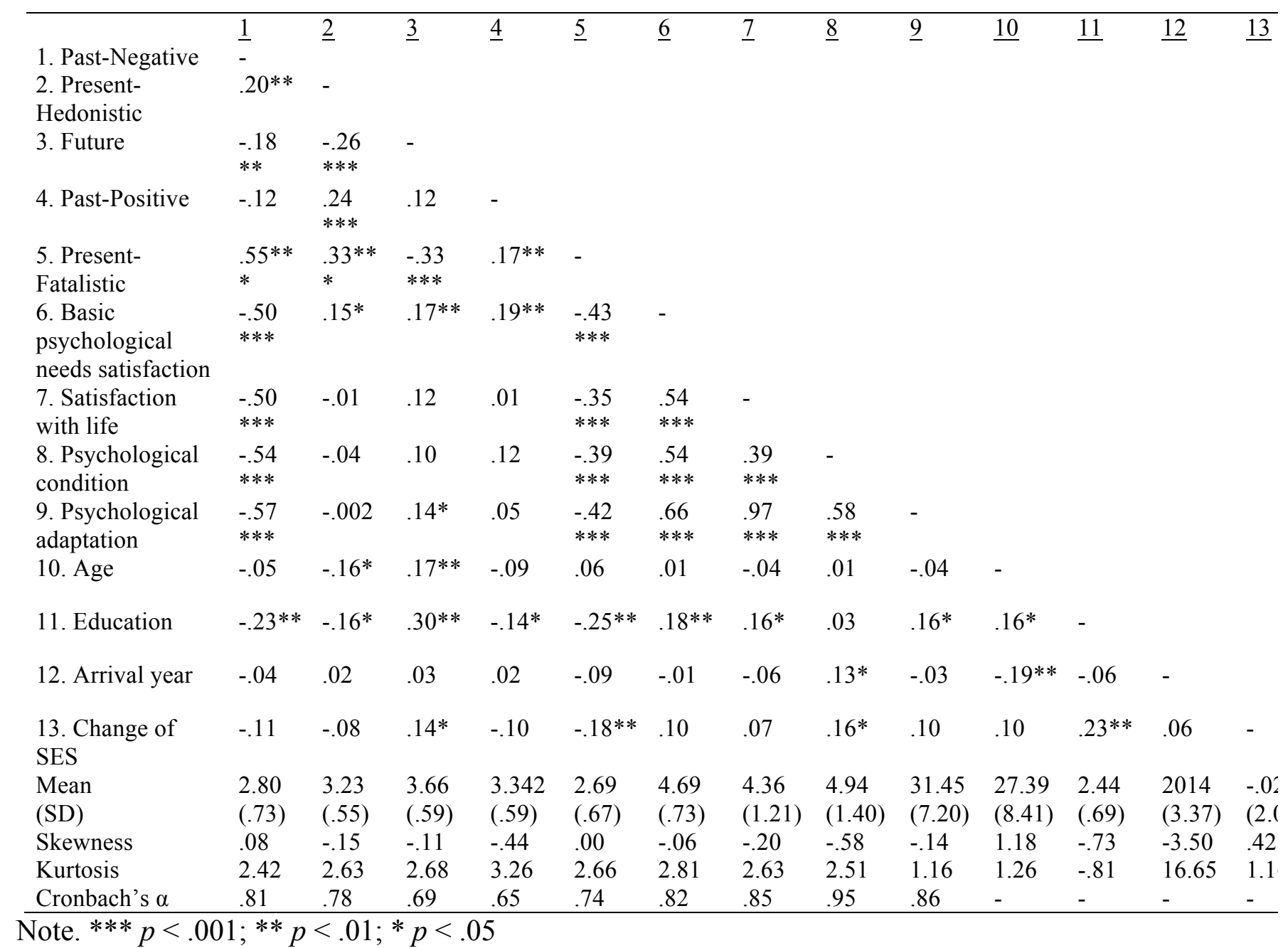

Table 2. The results of hierarchical multiple regression analysis for psychological adaptation 
with time perspectives as independent variables

\begin{tabular}{|c|c|c|c|c|c|}
\hline & $\underline{t}$ & $\underline{\beta}$ & $\underline{R^{2}}$ & $\underline{\Delta R^{2}}$ & $\Delta F$ \\
\hline Model 1 & & & .02 & .02 & $5.94 *$ \\
\hline Education & $2.44^{*}$ & .16 & & & \\
\hline Model 2 & & & .33 & .31 & $107.25^{* * *}$ \\
\hline Education & .54 & .03 & & & \\
\hline Past-Negative & $-5.62 * * *$ & -.57 & & & \\
\hline Model 3 & & & .34 & .01 & $4.55^{*}$ \\
\hline Education & .19 & .01 & & & \\
\hline Past-Negative & $-7.74 * * *$ & -.50 & & & \\
\hline Present-Fatalistic & $-2.13 *$ & -.14 & & & \\
\hline
\end{tabular}

Table 3. Model fit indices of latent class analyses solutions of time perspective typologies

\begin{tabular}{|c|c|c|c|c|}
\hline$\frac{\text { Number of }}{\text { classes }}$ & Entropy & $\underline{\mathrm{AIC}}$ & $\underline{\mathrm{BIC}}$ & Comparison of models \\
\hline 2 & .675 & 2145.465 & 2201.021 & $\begin{array}{c}2 \text { vs. } 1: \\
L R T=122.28, p<.001\end{array}$ \\
\hline 3 & .745 & 2118.915 & 2195.305 & $\begin{aligned} & 3 \text { vs. } 2: \\
L R T= & 37.41, p=.09\end{aligned}$ \\
\hline 4 & .67 & 2114.011 & 2211.235 & $\begin{array}{c}4 \text { vs. } 3: \\
L R T=16.41, p=.54\end{array}$ \\
\hline 5 & .69 & 2106.346 & 2224.404 & $\begin{array}{c}5 \text { vs. } 4: \\
L R T=19.08, p=.17\end{array}$ \\
\hline
\end{tabular}

Note. $\mathrm{AIC}=$ Akaike Information Criterion; $\mathrm{BIC}=$ Bayesian Information Criterion; LRT $=$ likelihood ratio test

Table 5. Results of the hierarchical multiple regression analysis for psychological adaptation with DBTP and DNTP indices as independent variables

\begin{tabular}{llllll}
\hline & $\underline{t}$ & $\underline{\underline{R^{2}}}$ & $\underline{\Delta R^{2}}$ & $\underline{\underline{\Delta F}}$ \\
Model 1 & $2.44^{*}$ & .16 & .02 & .02 & $5.94^{*}$ \\
Education & & & .30 & .28 & $92.49^{* * *}$ \\
Model 2 & .22 & .01 & & & \\
Education & $9.62^{* * *}$ & .54 & & .01 & $4.07 *$ \\
DNTP & & & .31 & & 35 \\
Model 3 & & & &
\end{tabular}




$\begin{array}{lcc}\text { Education } & .36 & .02 \\ \text { DNTP } & 6.21 * * * & .45 \\ \text { DBTP } & -2.02 * & -.14 \\ * p<.05 ; * * p<.01 ; * * * p<.001 & \end{array}$

DNTP $=$ deviation from the Negative Time Perspective index

$\mathrm{DBTP}=$ deviation from the Balanced Time Perspective index

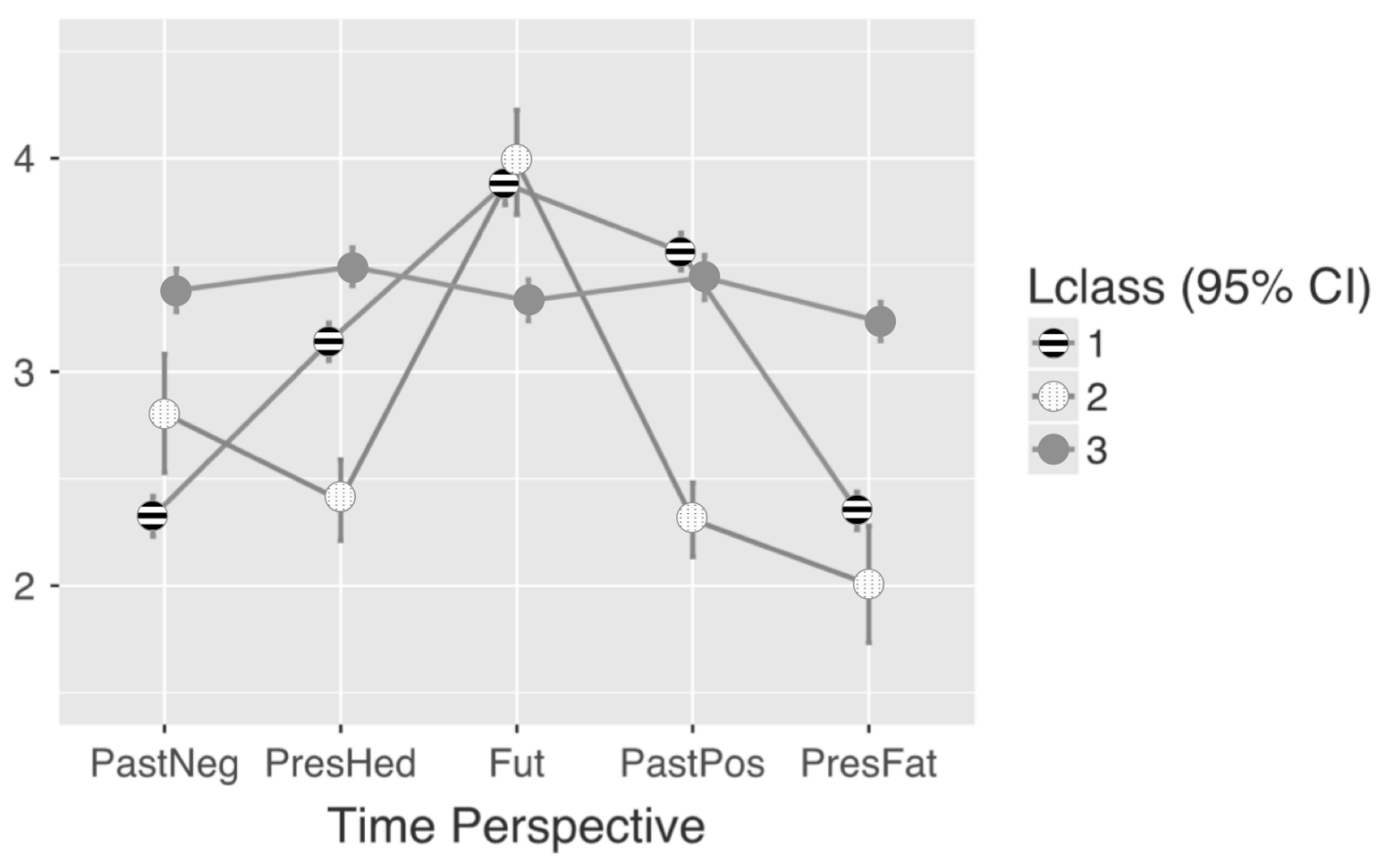

Figure 1. The results of three-latent class solution of time perspective typologies Note: PastNeg = Past Negative scale; PresHed $=$ Present Hedonistic scale; Fut $=$ Future scale; PastPos = Past Positive scale; PresFat $=$ Present Fatalistic scales dimensions 